\title{
MISCELANEA
}

COMUNICACIÓN PÓSTER VII CONGRESO NACIONAL DE LA SOCIEDAD CIENTÍFICA ESPAÑOLA DE ENFERMERÍA - SCELE. Mayo de 2014. UNIVERSIDAD DE ALICANTE.

\section{LA PIEL NO ENTIENDE DE CRISIS... O SI}

\section{SKIN DOES NOT CARE ABOUT CRISIS}

I. Malé Pegueroles, L. Guerrero, F. Caritg, M. Ferrández, B. Valero, J. Bellostes

EAP Mataró.7, EAP Premià de Mar. Institut Català de la Salut.

Contacto: imale.bnm.ics@gencat.cat 


\section{Palabras clave:}

hidratación, piel, enfermería.

\section{OBJETIVO:}

Evaluar los productos hidratantes ofertados en las grandes superficies comerciales según la relación coste/efectividad y sus indicaciones.

\section{MÉTODOS:}

En Atención Primaria (AP) se nota la repercusión de la crisis cuando, ante las recomendaciones habituales de enfermería para mantener la piel hidratada, escuchamos "Las cremas buenas son muy caras y no me las puedo permitir...".

En una piel seca el contenido lipídico en el estrato córneo ha disminuido mucho y en una piel deshidratada el contenido hídrico no llega al 10\%. Esta piel presentará aspereza y falta de extensibilidad. Además, pueden converger deslipidización y sequedad a la vez; la piel será áspera, seca, rugosa y con tirantez. También encontramos pieles grasas deshidratadas. La pérdida de agua transepidérmica (TEWL) depende del contenido lipídico de la epidermis. Con la edad baja la capacidad de retención de agua y disminuye el contenido acuoso.

\section{Diferenciamos entre:}

Sustancias humectantes: las de naturaleza higroscópica que retienen el agua ambiental. En ambientes secos extraen agua de las células de la piel. No modifican la TEWL. La más clásica es la Glicerina.

Sustancias con efecto oclusivo: Evitan la TEWL.

Se valoraron 29 pacientes entre 60 y 86 años, con signos de deshidración en EEII. Se les recomendó la aplicación diaria de vaselina a 11 de ellos y crema con aceite de argán a 8. El resto de usuarios siguieron consumiendo cremas con gel de aloe vera, aceite de oliva u otros. Se revaloró a los pacientes a las 24 h, a los 7 días y a los 15 días.

\section{RESULTADOS:}

La piel mantenía un aspecto más hidratado, a las $24 \mathrm{~h}$ y a los 7-15 días con vaselina, en un $100 \%$ de los pacientes; se objetivó una mejoría importante en el $70 \%$ de los pacientes que usaron crema con aceite argán pero a los 7-15 días. En el resto la mejoría sólo fue parcial. El precio de adquisición fue similar en todos los productos. No se detectaron diferencias significativas en la relación precio-efectividad.

\section{DISCUSIÓN:}

Las sustancias como el aceite de oliva o la glicerina se deben usar en grandes cantidades para poder ofrecer un efecto notorio. Los principios activos de acción media-fuerte, y que son de precio elevado, rosa mosqueta, aloe vera... se encuentran en pequeña cantidad en los productos de uso tópico. El aceite de argán es una sustancia bastante activa como para usar añadida en pequeñas cantidades. La vaselina hace descender la TEWL a cero.

A nivel de grandes superficies encontramos productos que, a precios razonables, cumplen bien su función. A los usuarios que se les recomendó utilizar estos productos mejoraron el estado de su piel.

Creemos que no sólo el hecho de aplicar cremas mejora el estado de la piel sino que insistir en los consejos desde la consulta de AP permite obtener resultados positivos. 